\title{
Phenotypic Characterization of Salmonella typhi from Clinical Specimens and Determination of the Drug Susceptibility Pattern of the Isolates
}

\author{
Tasnim Jabin ${ }^{1}$, Ehsan Al-din Siam ${ }^{1}$, Md Raihan Dipu ${ }^{1},{\text { Muhammad Asaduzzaman }{ }^{1}, \text { Md. Aftab Uddin }}^{1^{*}}$
}

1. Department of Microbiology, Stamford University Bangladesh, 51 Siddeswari Road, Dhaka 1217, Bangladesh

dc

10.30699/ijmm.15.2.189

\section{ABSTRACT}

Background and Aim: Salmonella typhi infection occurs in most endemic areas. Patients suspected of typhoid fever located in the Badda and Shantinagar localities of Dhaka were the studied population. A total of 107 blood specimens were collected.

Objective: This study attempted to determine the antibiotic susceptibility pattern of Salmonella typhi among different age and gender groups having clinical symptoms of typhoid fever.

Methods: The microorganisms obtained from blood specimens were identified by phenotypical and biochemical tests following standard protocols. Antibiotic susceptibility test was done by the Agar-disc-diffusion method to understand antibiotic susceptibility of the isolates. All the Salmonella typhi isolates were serologically confirmed using a commercial antisera kit.

Results and Conclusion: Out of 107, 74 Salmonella typhi isolates showed multidrug-resistant properties. Nalidixic acid, ampicillin, azithromycin, and ciprofloxacin showed high antibiotic resistance percentage. On the other hand meropenem, amikacin, gentamycin showed low antibiotic resistance. Age and sex groups also revealed significant attributes to the multidrug-resistant isolates. Multidrug-resistant pattern of the clinical isolates of Salmonella typhi of the current study has presented a matter of great public health concern in Dhaka city, Bangladesh. The first line of antibiotics can be prescribed, taking into consideration of age and gender. The sources of Salmonella typhi infection and mode of transmission must be identified.

Keywords: Salmonella typhi, Multidrug-resistant, Blood, Phenotypic, Resistance

\begin{tabular}{|c|c|c|c|c|}
\hline \multicolumn{3}{|c|}{ Received: 2020/05/12; } & Accepted: 2020/12/28; & Published Online: 2021/04/09 \\
\hline \multicolumn{2}{|c|}{ Corresponding Information: } & $\begin{array}{l}\text { Md. Aftab Uddin, } \\
\text { Email: aftab_mb1 }\end{array}$ & $\begin{array}{l}\text { tment of Microbiology, Stamfor } \\
\text { mforduniversity.edu.bd }\end{array}$ & versity Bangladesh, 51 Siddeswari Road, Dhaka 1217, Bangladesh. \\
\hline (c) & $\begin{array}{l}\text { Copyright (C) } 20 \\
\text { permits copy ar }\end{array}$ & $\begin{array}{l}\text { This is an original open } \\
\text { redistribution of the ma }\end{array}$ & $\begin{array}{l}\text { article distributed under the terms of } \\
\text { t in noncommercial usages with prop }\end{array}$ & $\begin{array}{l}\text { eative Commons Attribution-noncommercial } 4.0 \text { International License which } \\
\text { ion. }\end{array}$ \\
\hline
\end{tabular}

Use your device to scan and read the article online

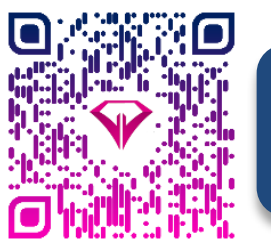

Jabin T, Siam E A, Dipu M R, Asaduzzaman M, Uddin A. Phenotypic characterization of Salmonella typhi from clinical specimens and determination of the drug susceptibility pattern of the isolates. Iran J Med Microbiol. 2021; 15 (2) :189-194

Download citation: BibTeX | RIS | EndNote | Medlars | ProCite | Reference Manager | RefWorks

Send citation to: $\Theta_{\text {Mendeley }} \mathbf{z}$ zotero $\overline{\text { Bif }}$ RefWorks

\section{Introduction}

Salmonella typhi is a major public health issue worldwide and mostly occurs in industrialized nations and developing countries (1). In Bangladesh, it has been estimated that the crude incidence of typhoid is 3.9 episodes/1,000 person-years in an urban slum (2). However, Bangladesh is a densely populated developing country where typhoid fever is around the year problem which sometimes takes epidemic proportions in this country. The morbidity and mortality rate of this disease indicates that this infection is life-threatening for human beings, especially for people of the developing world. Typhoid fever is a major health concern in such places due to their poor standard of hygiene, inappropriate sewage 
treatments, and lack of drinking water resources (3). Salmonella typhi is a Gram-negative, rod-shaped bacteria, non-spore-forming, motile, microscopic living creatures, and facultative anaerobes belonging to the family Enterobacteriaceae (4). Salmonella typhi is usually isolated from humans, retail meat (5), and different animal origin. This bacterium spreads through people who consume contaminated food through different sources such as stool, urine, and water contaminated with sewage (6). Typhoid fever, also known as enteric fever, caused by Salmonella typhi is a global health problem (7). The occurrence of Salmonella typhi takes place mostly due to the misuse of drugs, overuse of antibiotics, and inappropriate prescribing practices by a general practitioner (8). An appropriate and authentic identification and sensitivity testing are necessary for the proper treatment of patients with typhoid fever. The present study provides information regarding the phenotypic characterization of Salmonella typhi along with the antimicrobial drug susceptibility pattern in the clinically suspected cases of typhoid fever, particularly from the blood specimen.

\section{Materials and Methods}

About $1.5 \mathrm{ml}$ of child blood and $5 \mathrm{ml}$ of adult blood were collected from suspected individuals' respective categories. The blood samples were aseptically transferred to blood culture broth and incubated as recommended procedures. Each tube was carefully labeled with the sample number. The collected blood samples were incubated overnight at $37^{\circ} \mathrm{C}$ for 18 to 24 hours. Tubes that show turbidity were subcultured on Xylose Lysine Deoxycholate agar at $37^{\circ} \mathrm{C}$. Microscopic analysis of the isolates was performed for the determination of bacterial size, shape, and staining properties (9). Each culture underwent a Gram staining procedure. The biochemical tests for Salmonella typhi were KIA test, Nitrate Reduction test, Oxidase test, Catalase test, Indole test, MR-VP test, Citrate utilization test, $\mathrm{H}_{2} \mathrm{~S}$ production test, Sugar fermentation tests (10-11). Bacterial susceptibility test was done in vitro by the agar-disc-diffusion method (Kirby Bauer technique) (12). Bacteria were categorized as resistant or susceptible to each antimicrobial agent according to standard CLSI guidelines 2013 (20). The antibiotic discs used in this experiment were Ampicillin (10 $\mu \mathrm{g})$, Azithromycin (15 $\mu \mathrm{g})$, Nalidixic Acid $(30 \mu \mathrm{g})$, Amikacin $(30 \mu \mathrm{g})$, Cefixime (5 $\mu \mathrm{g})$, Cefuroxime $(30 \mu \mathrm{g})$, Ceftriaxone (30 $\mu \mathrm{g})$, Ciprofloxacin (5 $\mu \mathrm{g})$, Cotrimoxazole (30 $\mu \mathrm{g})$, Chloramphenicol (30 $\mu \mathrm{g})$, Gentamicin (10 $\mu \mathrm{g})$, Meropenem. $(10 \mu \mathrm{g})$, Levofloxacin $(30 \mu \mathrm{g})$. Antibiotics were chosen according to evidence of safety, effectiveness, and health relevance.

Zone of inhibition data from the Kirby-Bauer disk diffusion test compiled using the spreadsheet (MS Excel, Microsoft Corporation, USA) and used as input file in Bac Link software to format the data for further analysis using WHONET-2019 software (WHO Collaborating Centre for Surveillance of Antimicrobial Resistance, USA). The diameter of growth inhibition around the discs was measured as resistant, according to the Clinical and Laboratory Standards Institute (13). The reference strain of Salmonella typhimurium ATCC 14028 was used as quality control for antimicrobial susceptibility tests. Normal saline was used as negative control for antimicrobial susceptibility tests.

All the Salmonella typhi isolates $(n=107)$ were serologically confirmed using a commercially available antisera kit (Mast Group, UK). Isolates were subcultured on Muelller Hinton agar plates about $18 \mathrm{~h}$ incubation; the serological test was done by conventional agglutination test.

\section{Results \& Discussion}

In Bangladesh, antibiotic resistance patients are becoming progressively greater due to the lack of microbiological research, changing microbial and antibiogram patterns. The appropriate treatment and preventative measures have become a challenge to the clinician. The study was conducted to know the antibiotic resistance pattern of Salmonella typhi after investigating 107 clinically suspected patients of typhoid fever. In our analysis, all suspected isolates were examined for the presence of Salmonella typhi red colonies with black centers. Salmonella typhi isolates were confirmed by gram staining microscopic analysis and distinctive kind of biochemical examination/analysis/test (Table 1) and standard serological methods

Table 1. Biochemical tests for the isolates bacteria

\begin{tabular}{|c|c|c|c|c|c|c|c|c|c|c|c|}
\hline $\begin{array}{l}\text { Assumed } \\
\text { Organism }\end{array}$ & $\begin{array}{r}\text { TS } \\
\text { Slant } \\
\text { Ge }\end{array}$ & $\begin{array}{l}\text { SI } \\
\text { Butt } \\
\text { ias }\end{array}$ & $\begin{array}{l}\text { Indole } \\
\text { Test }\end{array}$ & $\begin{array}{l}\text { MR } \\
\text { Test }\end{array}$ & $\begin{array}{l}\text { VP } \\
\text { Test }\end{array}$ & $\begin{array}{l}\text { Citrate } \\
\text { Test }\end{array}$ & $\begin{array}{c}\text { Oxidase } \\
\text { Test }\end{array}$ & $\begin{array}{c}\text { Catalase } \\
\text { Test }\end{array}$ & $\begin{array}{c}\text { KIA } \\
\text { Slant } \\
\text { Butt Gas }\end{array}$ & $\begin{array}{c}\text { Sugar } \\
\text { Fermentation } \\
\text { Test }\end{array}$ & $\begin{array}{c}\text { Nitrate } \\
\text { Reduction } \\
\text { Test }\end{array}$ \\
\hline $\begin{array}{c}\text { Salmonella } \\
\text { spp. }\end{array}$ & $\mathbf{R}$ & + & - & + & - & - & - & - & $Y+$ & - & + \\
\hline
\end{tabular}

${ }^{*} \mathrm{TSI}=$ Triple Sugar Iron, KIA= Kligler's Iron Agar , Y = Yellow (Acid), R = Red (Alkaline), MR = Methyl red, VP =Voges-Proskauer, 
In our investigation, a total of 107 patients were suspected to be suffering typhoid fever, of male and female gender between the age group of 5 months to 60 years old were recruited between the study period from September 2019 to December 2019 (Figure 1a). In our analysis sixty-seven patients (63\%) were male and forty patients (37\%) were female (Figure 1b). Male having predominance over females as male patients were more affected (63\%) than female patients (37\%). Moreover, patients' ages ranged from 11-20 (Figure 1a)years showing the highest degree of susceptibility pattern (37n) for the typhoid fever followed by $21-30$ years $(26 n), 5 m-10 y(32 n)$. The patients' age sort/classify from 1 year to 30 years was more affected in terms of male and female patients whereas the lowest incidence rate of typhoid fever was between 41 to 60 years.
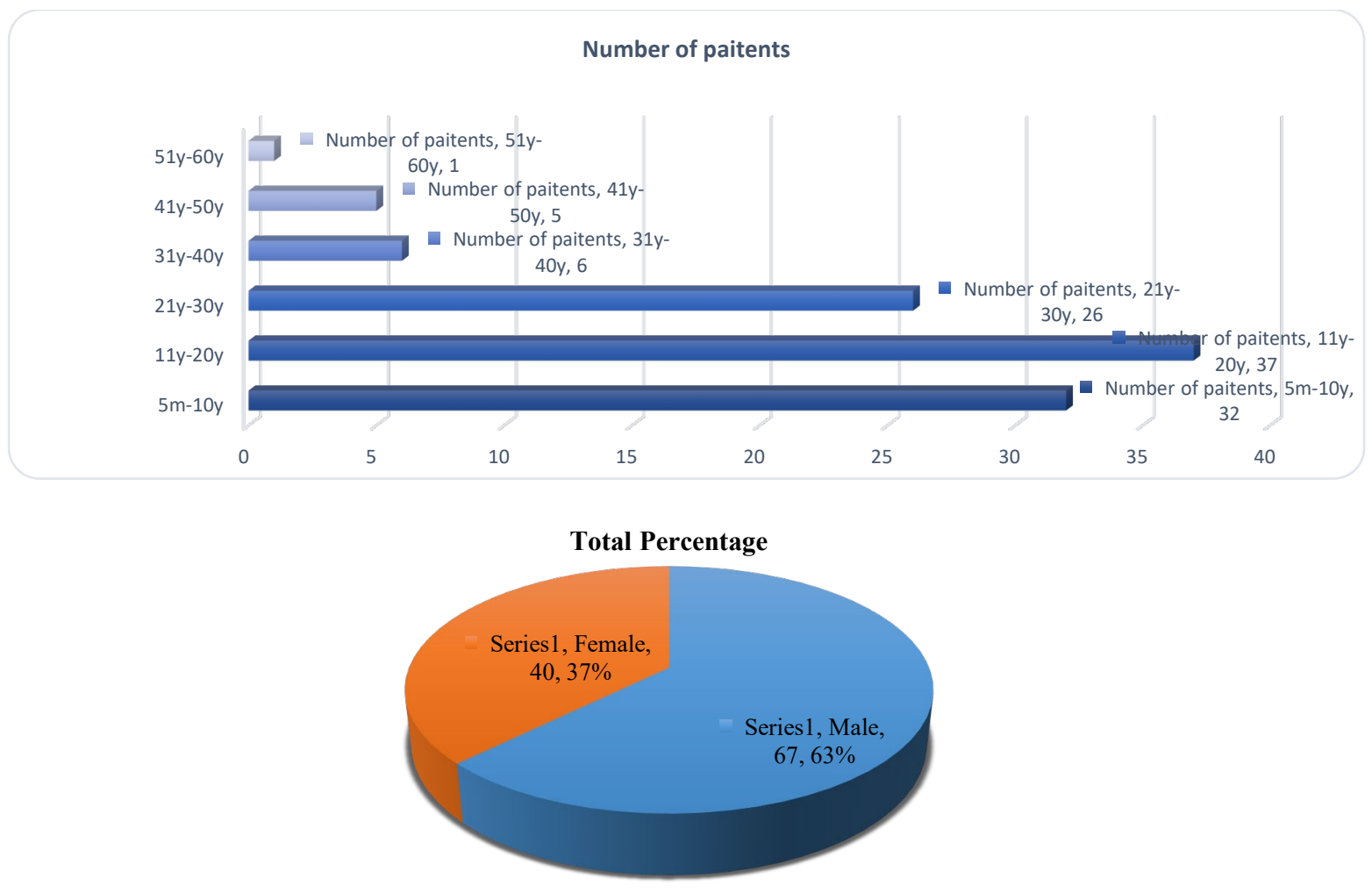

Figure 1. a: Distribution of age groups among respondents . b: Distribution of gender groups among respondents

With regard to antibiogram profiles of Salmonella typhi isolates, all the clinical isolated organisms were tested for the determination of antibiotic susceptibility patterns. Higher rates of resistance were found against various antibiotics in most of the Salmonella typhi isolates. Out of 107, 74 isolates were found to be multidrug-resistant. In phenotypic antimicrobial sensitivity test, among the 107 isolates, all tested resistant against nalidixic acid, most were resistant amoxicillin 53.3\% $(n=58 ; 95 \%, \mathrm{Cl}$ : 43.4$62.9 \%)$ and azithromycin $29 \%(n=31 ; 95 \%, \mathrm{Cl}: 21.6-$ 39.6). Sensitivity to meropenem and amikacin was higher (94.4\% and 93.5\%, respectively). However, male patients $58.2 \%$ ( $n=62 ; 95 \% \mathrm{Cl}$ : 45.5-69.9) were more resistant than female patients $45 \%$ ( $n=48 ; 95 \%$ $\mathrm{Cl}$ : 429.6-61.3) against ampicillin according to the widely used standardized international terminology and WHONET 2019 analysis (Table 2). A similar pattern of antibiotic resistance has been observed in the previous studies done by the Clinical Microbiology Laboratory of icddr,b, Bangladesh from 2006 to 2010(14). Similar to that analysis another study in Bangladesh during 2006-2007 showed that $100 \%$ S. Typhi isolates were resistant to nalidixic acid (15). Ceftriaxone, meropenem, amikacin, gentamicin were found similarly effective against isolates obtained from male and female patients.

In the present study 38 isolates were found to be resistant to at least 2 antibiotics, 18 isolates were found to be resistant to 3 antibiotics, 11 isolates were resistant to 4 antibiotics and 7 isolates were resistant to 5 or more antibiotics ( $\underline{\text { Table } 3}$ ). 
Table 2. Antibiotic resistance of isolates against regularly used antibiotics to treat Salmonella typhi infection

\begin{tabular}{|c|c|c|c|c|c|c|c|c|c|}
\hline \multirow{2}{*}{ Antibiotic name } & \multirow{2}{*}{ Antibiotic class } & \multirow{2}{*}{ Code } & \multirow{2}{*}{ Breakpoints } & \multicolumn{2}{|c|}{ Male } & \multicolumn{2}{|c|}{ Female } & \multicolumn{2}{|c|}{ Overall } \\
\hline & & & & $\% \mathrm{R}$ & 95\%C.I. & $\% R$ & 95\%C.I. & $\% R$ & 95\%C.I. \\
\hline Ampicillin & Penicillins & AMP & 14- 16 & 58.2 & $45.5-69.9$ & 45 & $29.6-61.3$ & 53.3 & $43.4-62.9$ \\
\hline Cefuroxime & Cephems & CXM & $15-22$ & 14.7 & $5.5-31.8$ & 21.7 & $8.3-44.2$ & 17.5 & $9.2-30.4$ \\
\hline Ceftriaxone & Cephems & CRO & $20-22$ & 0.0 & $0.0-6.8$ & 2.5 & $0.1-14.7$ & 0.9 & $0-5.8$ \\
\hline Cefixime & Cephems-Oral & CFM & $16-18$ & 9.0 & 3.7-19.1 & 15.0 & $6.2-30.5$ & 11.2 & $6.2-19.1$ \\
\hline Meropenem & Penems & MEM & 20- 22 & 0.0 & $0.0-6.8$ & 2.5 & $0.1-14.7$ & 0.9 & $0-5.8$ \\
\hline $\begin{array}{l}\text { Amikacin } \\
\text { Gentamicin } \\
\text { Nalidixic acid } \\
\text { Ciprofloxacin } \\
\text { Levofloxacin } \\
\text { Trimethoprim } \\
\text { Azithromycin } \\
\text { Chloramphenicol }\end{array}$ & $\begin{array}{l}\text { Aminoglycosides } \\
\text { Aminoglycosides } \\
\text { Quinolones } \\
\text { Quinolones } \\
\text { Quinolones } \\
\text { Folate pathway } \\
\text { inhibitors } \\
\text { Macrolides } \\
\text { Phenicols }\end{array}$ & $\begin{array}{l}\text { AMK } \\
\text { GEN } \\
\text { NAL } \\
\text { CIP } \\
\text { LVX } \\
\text { SXT } \\
\text { AZM } \\
\text { CHL }\end{array}$ & $\begin{array}{c}15-16 \\
13-14 \\
14-18 \\
21-30 \\
17-20 \\
11-15 \\
S>=13 \\
13-17\end{array}$ & $\begin{array}{c}0.0 \\
0.0 \\
100 \\
19.4 \\
9.4 \\
29.5 \\
28.4 \\
13.4\end{array}$ & $\begin{array}{c}0.0-6.8 \\
0.0-6.8 \\
93.2-100 \\
11.1-31.2 \\
3.9-19.9 \\
18.9-42.7 \\
18.3-40.9 \\
6.7-24.5\end{array}$ & $\begin{array}{c}0.0 \\
2.5 \\
100.0 \\
27.5 \\
12.5 \\
23.1 \\
32.5 \\
15.0\end{array}$ & $\begin{array}{c}0.0-10.9 \\
0.1-14.7 \\
89.1-100 \\
15.1-44.1 \\
4.7-27.6 \\
11.7-39.7 \\
19.1-49.2 \\
6.2-30.5\end{array}$ & $\begin{array}{c}0.0 \\
0.9 \\
100 \\
22.4 \\
10.6 \\
27 \\
29 \\
14\end{array}$ & $\begin{array}{c}0.0-4.3 \\
0-5.8 \\
95.7-100 \\
15.2-31.7 \\
5.7-18.5 \\
18.8-37.0 \\
21.6-39.6 \\
8.3-22.4\end{array}$ \\
\hline
\end{tabular}

${ }^{*}$ C.I.= Confidence Interval

Table 3. Prevalence of multidrug-resistant isolates

No. of ineffective antibiotics

Two (2)

Three (3)

Four (4)

Five (5) and above
No. of S. typhi isolates $(n=74)$

38

18

11

7
Age and sex were found to be a risk factor for antibiotic susceptibility of Salmonella typhi isolates. Age and gender have a significant effect on antibiotic resistance. All infants and children ( $<1$ to 10 years) regardless of sex were found to be Salmonella typhi
MDR resistance. Male patients were more resistant than female patients of the age group from 31 to 40 years. Age and sex-specific antimicrobial susceptibility patterns of Salmonella typhi are presented in Table 4.

Table 4. Multidrug resistance pattern of Salmonella typhi, disk diffusion method in terms of gender and patients age ( $\mathrm{n}=74$ )

\begin{tabular}{|c|c|c|c|c|c|c|c|}
\hline \multirow{2}{*}{ Gender } & \multicolumn{7}{|c|}{ Age group (years) } \\
\hline & $<1$ & $1-10$ & $11-20$ & $21-30$ & $31-40$ & $41-50$ & $51-60$ \\
\hline Female & AMP, NX & $\begin{array}{c}\text { AZT, CEF,CXM, } \\
\text { NX, CTX }\end{array}$ & $\begin{array}{c}\text { AZT CEF, CXM, } \\
\text { NX, CPL, CTX, } \\
\text { AMK }\end{array}$ & $\begin{array}{c}\text { AMP , NX, } \\
\text { CXM,MEM,GEN,CPL }\end{array}$ & AZT, NX, CTX & - & - \\
\hline Male & AMP, NX & $\begin{array}{c}\text { AZT, CEF,CXM, } \\
\text { NX, CTX. } \\
\text { AMP,CPL,CTX }\end{array}$ & $\begin{array}{l}\text { AZT, AMP, NX, } \\
\text { CPL, CTX }\end{array}$ & $\begin{array}{c}\mathrm{NX}, \mathrm{CTX}, \mathrm{AMP}, \mathrm{CPL}, \\
\text { AZT,CXM }\end{array}$ & $\begin{array}{l}\text { NX, CTX, } \\
\text { AMP,CPL, } \\
\text { AZT,CXM }\end{array}$ & AMP, NX & $\mathrm{NX}, \mathrm{CPL}$ \\
\hline
\end{tabular}

${ }^{*}$ Ampicillin=AMP, Nalixic acid= NX, Azithromycin=AZT, Cefixime=CEF, Cefuroxime=CXM, Cotrimoxazole=CTX, Chloramphenical=CPL, Amikacin=AMK, ,Merephenom=MEM, Gentamycin=GEN

This current data is very alarming for us since some isolates keep resistance patterns against commonly used antibiotics. This shows an alarming increase in multidrug resistance of pathogenic microorganisms in 
Bangladesh supported by previous studies (16). In this research, however, we found very high microbialresistance to nalidixic acid and first-line antibiotics including ampicillin, azithromycin, and ciprofloxacin. The findings were in agreement with previous studies (17-18). We also obtained from that ceftriaxone, meropenem, amikacin, and gentamycin were more effective against Salmonella typhi isolates, considering age and gender differences. However, any isolate that showed resistance against nalidixic acid and clinicians advised switching over to another antibiotic (19) as nalidixic acid has proven ineffective in our study.

All the Salmonella typhi isolates of this study were identified by standard serological methods using commercially available antisera (Mast Group, UK). In this study, the most prevalent serogroup was 09. All isolates showed the same serogroup and they were not distinguished as untypable. The serological classification scheme is based on antigenic variation in bacterial surface molecule variability (20).

\section{Conclusion}

The findings of the present study indicated that Salmonella typhi in clinical blood specimens is seriously turning out to be a matter of concern due to their multi-drug resistance (MDR) pattern. This research study has much strength. These results are important to physicians as a basis for the prescription of effective antibiotics for typhoid fever patients, considering age and sex differences. These findings are also important to physicians for preventing the emerging of resistant strains by incorrect indications. Incomplete treatments and over the counter availability may be the factors contributing to the emergence of drug resistance. A documented trend antibiotic resistance data analysis can be performed regularly to assist guide in the routine administration of less resistant antibiotics. Although the antibiotic susceptibility pattern approach for the disk diffusion method does not reveal a reliable antibiotic susceptibility profile. Further studies and multi-level analysis with the massive number of clinical specimens are recommended to validate our current study, besides research and developments regarding the discovery of the new antibiotics is also mandatory.

\section{Acknowledgment}

We thank the Department of Microbiology, Stamford University Bangladesh for funding support throughout our study.

\section{Conflict of Interest}

The authors have no conflict of interest.

\section{References}

1. Selvaraj R, Das R, Ganguly S, Ganguli $M$, Dhanalakshmi S, Mukhopadhayay SK. Characterization and antibiogram of Salmonella spp. from poultry specimens. J Microbiol Antimicrob. 2010; 2(9): 123-6.

2. Bhan MK, Bahl R, Bhatnagar S. Typhoid and paratyphoid fever. The Lancet. 2005; 366(9487):749-62. [DOI:10.1016/S01406736(05)67181-4]

3. Crump JA, Luby SP, Mintz ED. The global burden of typhoid fever. Bull World Health Organ. 2004; 82(5): 346-53.

4. Cabral JPS. Water Microbiology. Bacterial Pathogens and Water. Int J Environ Res Public Health. 2010; 201(7): 3657-703. [DOI:10.3390/ijerph7103657] [PMID] [PMCID]

5. Zhang S, Kingsley R. A, Santos RL, AndrewsPolymenis $H$, Raffatellu $M$, Figueiredo J, et al. Molecular pathogenesis of Salmonella enterica serotype typhimurium induced diarrhea. Infect. Immun. 2003; 71(1):1-12. [DOI:10.1128/IAI.71.1.112.2003] [PMID] [PMCID]

6. Nagshetty K, Channappa ST, Gaddad SM. Antimicrobial susceptibility of Salmonella typhi in India. J Infect Dev Countries. 2010; 4(2):70-3. [DOI:10.3855/jidc.109] [PMID]

7. Rahman MA. Antimicrobial Resistance Patterns of Salmonella Typhi Isolated from Stool Culture. Chattagram Maa-O-Shishu Hosp Med Coll J. 2015; 14(1):26-30. [DOI:10.3329/cmoshmcj.v14i1.22876]

8. Ammah A, Nkuo-akenji T, Ndip R, Deas JE. An update of concurrent malaria and typhoid fever in Cameroon. Trans. R. Soc. Trop. Med. Hyg. T ROY SOC TROP MED H. 1999; 93:127-9. [DOI:10.1016/S00359203(99)90282-1]

9. Kreig NR., Holt JG, Bergey DH. Bergeys Manual of Systematic Bacteriology. 1st ed. East Preston street, Baltimore; 1984.

10. Collee JG, Marmion BP, Fraser AG. Practical Medical Microbiology. 14th ed. Churchill Livingstone, New York; 1996.

11. Cheesbrough M. Medical Laboratory Manual for Tropical Countries. Vol 2. Cambridgeshire (UK); 1984.

12. Bauer A.W, Kirby W.M.M, Sheris J.C., Truck M. Antibiotic susceptibility testing by a standardized single disc method. Am J Clin Path 1966; 145:225-30. 
13. Clinical and Laboratory Standards Institute. Performance Standards for Antimicrobial Susceptibility Testing; Seventeenth Information Supplement, CLSI document M100-S17. Clinical and Laboratory Standards Institute, Wayne, Pa, USA; 2011

14. Azmi I, Akter M, HasanTN, Akter F, Sultana H, Banik $D$, et al. Mechanism of Fluoroquinolone Resistance in Salmonella Typhi. 8th International Conference on Typhoid Fever and Other Invasive Salmonellosis. 2013; 34-5.

15. Rahman AKMM, Ahmad M, Begum RS, Hossain MZ, HO J, Que Sa, et al. Prevalance of typhoid fever among the children in a semi urban area of Bangladesh. J Dhaka Med Coll. 2006; 20(1): 37-43. [DOI:10.3329/jdmc.v20i1.8570]

16. Mannan A. A cross sectional study on antibiotic resistance pattern of Salmonella Typhi clinical isolates from Bangladesh. Asian Pac J Trop Biomed. 2014; 4(4): 306-11. [DOI:10.12980/APJTB.4.2014C770] [PMID] [PMCID]

17. Ahmed D, D'Costa LT, Alam K, Nair GB, Hossain MA. Multidrug-resistant Salmonella enterica serovar typhi isolates with high-level resistance to ciprofloxacin in Dhaka, Bangladesh. Antimicrob Agents Chemother. 2006; 50:3516-7. [DOI:10.1128/AAC.00667-06] [PMID] [PMCID]

18. Akter L, Hassan M, Ahmed Z. Present status and antibiotic sensitivity pattern of Salmonella typhi and S. paratyphi in different age group hospitalized patients in Dhaka city, Bangladesh. IOSR J Pharm Biol Sci. 2012; 4:27-30. [DOI:10.9790/3008-0432730]

19. Madhulika U, Harish BN, Pajra SC. Current pattern in antimicrobial susceptibility of Salmonella typhi isolates in Pondicherry. Ind J Med. Res. 2004; 120(2):111-4.

20. Hernández JR, Martínez-Martínez L, Cantón R, Coque TM, Pascual A, the Spanish Group for Nosocomial Infections (GEIH). Nationwide study of Escherichia coli and Klebsiella pneumoniae producing extended-spectrum -lactamases in Spain. Antimicrob. Agents Chemother. 2005; 49: 2122-5. 